\title{
Microstructures and Tensile Mechanical Properties of Consolidated Copper
}

\author{
Cun Liang ${ }^{a}$, Mingxing Ma ${ }^{b *}$, Deliang Zhang ${ }^{a}$ \\ ${ }^{a}$ State Key Laboratory of Metal Matrix Composites, School of Materials Science and Engineering, \\ Shanghai Jiao Tong University, Shanghai 200240, China \\ ${ }^{b}$ Department of Materials and Chemical Engineering, Zhongyuan University of Technology, \\ Zhengzhou 450007, China
}

Received: October 8, 2015; Revised: October 22, 2015

\begin{abstract}
Two consolidated copper samples were prepared by consolidation of a gas atomized powder using two different routes of spark plasma sintering (SPS), respectively. The first route was direct SPS of copper powder at $800{ }^{\circ} \mathrm{C}$ for 10 minutes, and the second route was compacting copper powder by die-pressing to produce a powder compact followed by SPS of the powder compact at $800{ }^{\circ} \mathrm{C}$ for 10 minutes. The microstructures and tensile mechanical properties and the fracture surfaces of specimens have been studied. It was found that the level of consolidation of the sample made using Route 1 was higher than that of the sample made using Route 2, as reflected by the relatively higher strength and better ductility of the first sample than those of the second sample. The lower consolidation level of the second sample was depicted by the higher volume fraction of cavities in the fracture surfaces of specimens which were formed by separation of the powder particles at the weakly bonded interparticle boundaries. The grain sizes of the first sample were larger than those of the second sample. The reasons for the differences in the levels of consolidation and grain sizes associated with two SPS routes are discussed.
\end{abstract}

Keywords: powder metallurgy, copper, microstructure, mechanical properties, spark plasma sintering

\section{Introduction}

Powder metallurgy can increase the material utilization, which is an ideal process to fabricate high performance and low cost materials ${ }^{1-6}$. The copper and copper alloy products prepared by powder metallurgy have good thermal conductivity, high corrosion resistance and good surface finish, and they are nonmagnetic. Due to these favourable atrributes, powder metallurgy copper and copper alloy products are widely used in automotive, appliance, electronics, communication and other areas, and thus play an important role in industrial production ${ }^{7-12}$. Compared with conventional sintering methods, the spark plasma sintering (SPS) can save energy and time, improve the equipment efficiency. The material made by SPS have grains with sizes in narrow ranges and excellent mechanical properties ${ }^{13-18}$. In our research, we utilized two different routes of SPS to prepare two consolidated copper samples from a gas atomized copper powder with a purity of $99.5 \%$ and particle sizes smaller than $75 \mu \mathrm{m}$. The major issue associated with rapid thermo mechanical powder consolidation techniques such as SPS is whether all interparticle boundaries in the powder compact are transformed into grain boundaries or interfaces within the short processing time covering heating, holding and sintering of the powder and the powder compact. To address this issue, we studied the microstructures and room temperature tensile mechanical properties and fracture behavior at the strain rate $5 \times 10^{-4} \mathrm{~s}^{-1}$ of the two copper samples produced by different SPS routes

*e-mail: manager92@163.com respectively. We hoped that through this study the true nature of the mechanical properties of the two copper samples can be elucidated in relation to their microstructure.

\section{Experimental Procedure}

The first copper sample was prepared by spark plasma sintering (SPS) a gas atomized copper powder (purity: $99.5 \%$, particle sizes $<75 \mu \mathrm{m}$ ) directly at $800{ }^{\circ} \mathrm{C}$ with a holding time of 10 minutes under a pressure of $50 \mathrm{MPa}$. To make the second copper sample, the gas atomized copper powder was first die pressed at room temperature under a pressure of $560 \mathrm{MPa}$ and with a holding time of 5 minutes to make a copper powder compact with a relative density of $98.96 \%$. The diameter of the green powder compact was $28 \mathrm{~mm}$. The powder compact was consolidated by SPS at $800{ }^{\circ} \mathrm{C}$ with a holding time of 10 minutes and under a pressure of $50 \mathrm{MPa}$ to prepare the second copper sample. Dog-bone shaped tensile test specimens with cross-sectional dimensions of $1.9 \times 1.6 \mathrm{~mm}^{2}$ and a gauge length of 10 were cut from the two copper samples perpendicular to the pressing direction using an electro discharge wire cutting machine. The tensile testing was performed using a Zwick T1-FR020.A50 electronic universal material testing machine at room temperature with a strain rate of $5 \times 10^{-4} \mathrm{~s}^{-1}$. For each sample, three specimens were tested. The microstructures and the fracture surfaces of the tensile test specimens were examined by using scanning electron microscopy (Sirion 
200 and NOVA NanoSEM 230). An electron backscattered diffraction (EBSD) detector attached to the SEM was used to produce the Band Contrast and Euler angles (BC+E1-3) maps and the inverse pole figure (IPF) and pole figure (PF) orientation maps of the consolidated copper samples which were used to show the grains and levels of texturing of the two samples.

\section{Results and Discussion}

As depicted in Figure 1, the microstructures of the two consolidated copper samples both consisted of equiaxed grains with sizes in the ranges of $0.05-15 \mu \mathrm{m}$ for the first copper sample and 0.05-5 $\mu \mathrm{m}$ for the second copper samples. The grains in both samples also contained a large number of $<111>$ twins, and the number density of the twins in the second copper sample was clearly higher than that in the first copper sample, as shown in Figure 1a, b. Since the stacking fault energy of copper is quite low, so it is easy for the plastic strains of the powder particles caused by powder compacting during die-pressing and SPS to induce annealing twins when the powder compact was heated. The die-pressing of the copper powder prior to SPS caused a larger amount of plastic deformation which in turn can induce formation of a higher density of twins during heating the powder compact, so it is not surprising to observe a larger density of twins in the second copper sample.

As shown in Figure 2, the microstructures of the first copper sample had a substantial fraction of grains with substructures and a small fraction of recrystallized grains, while the second copper sample had a substantial fraction of recrystallized grains and a small fraction of grains with substructures. As shown in Figure 2e, f, there are a larger fraction of low anagle grain boundaries with misorientations of less than $10^{\circ}$ in the first copper sample, in agreement with the observation of a higher fraction of grains with substructures in this sample. When using SPS to consolidate the copper powder at $800^{\circ} \mathrm{C}$, rapid proliferation and activation of the powder particles surfaces occur, and the powder particles rearrange themsevels and are plastically deformed during pressing leading to an increase of the dislocation density in

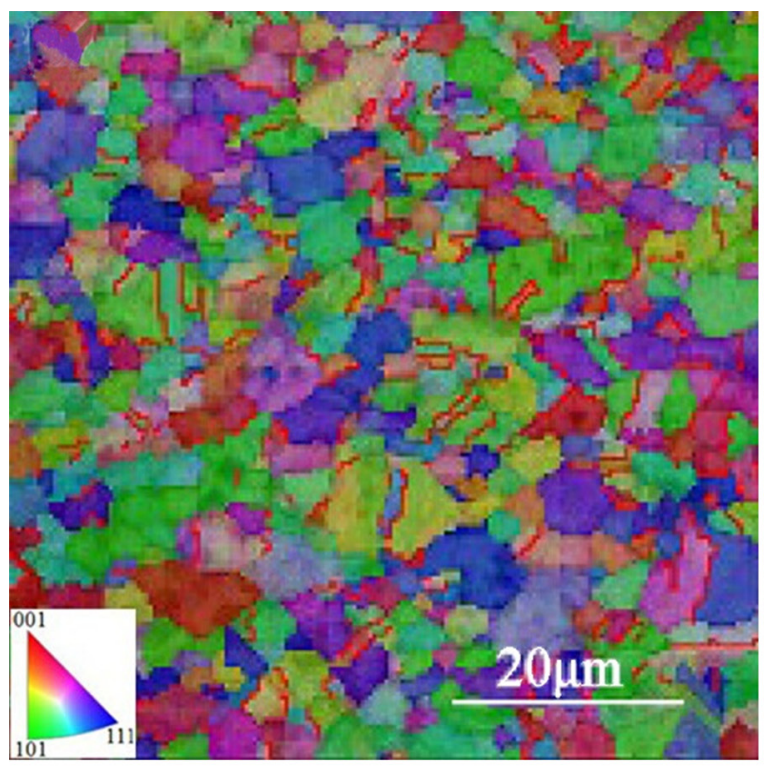

(a)

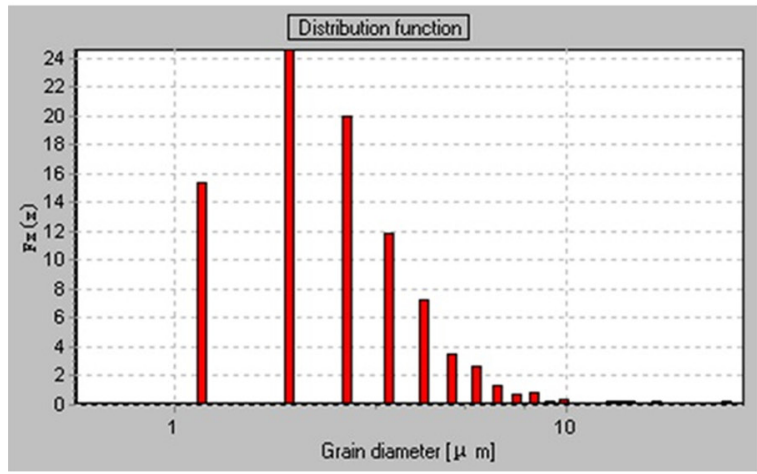

(c)

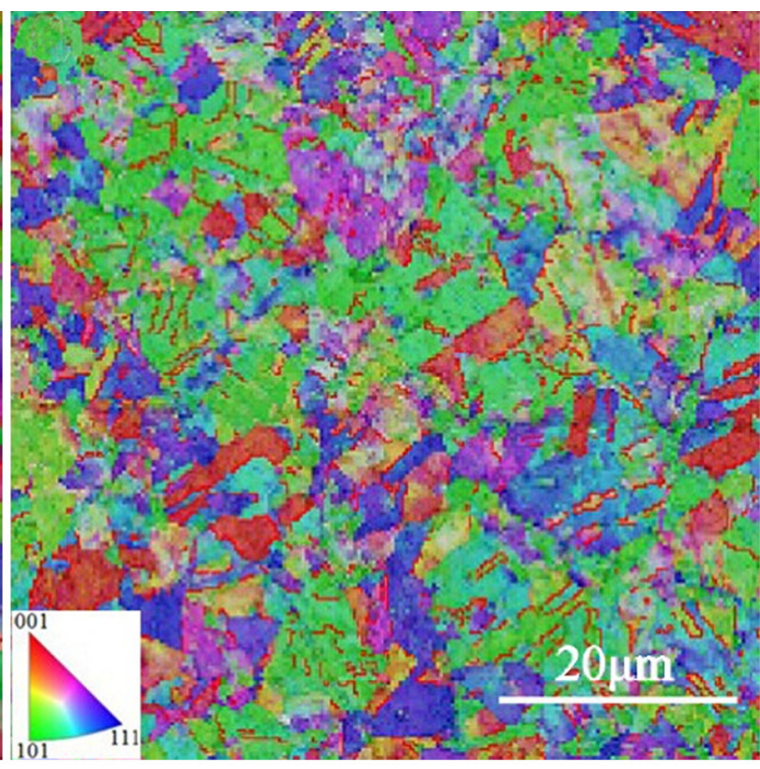

(b)

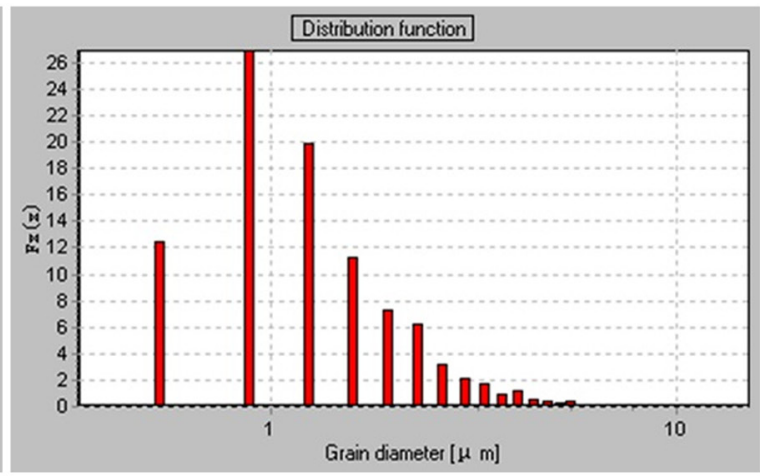

(d)

Figure 1. (a) and (b) The crystal orientation Z-axis IPF contrast maps of the first sample and the second sample; (c) and (d) The grain diameter distribution function of the first sample and the second sample; respectively. 


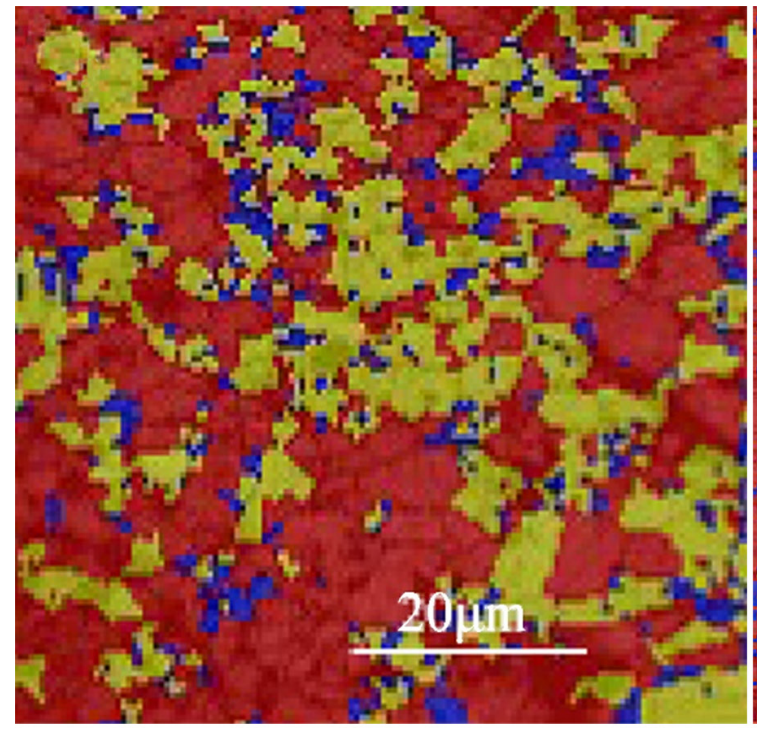

(a)

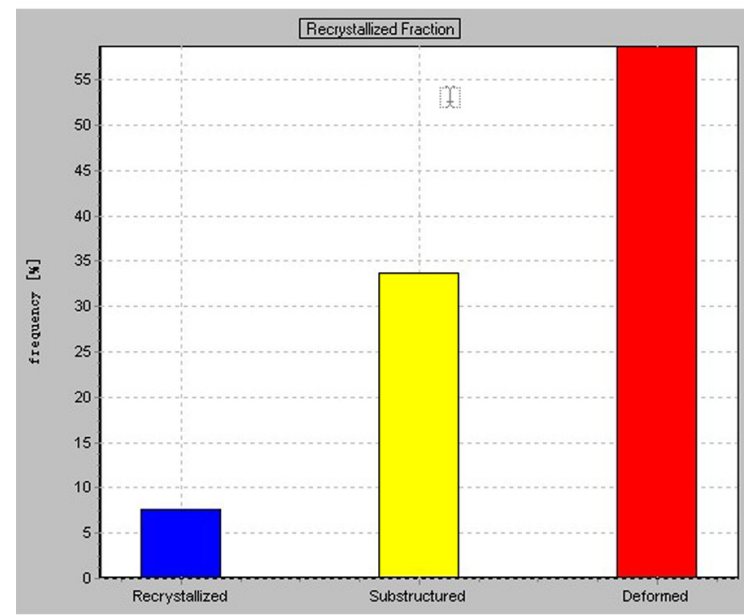

(c)

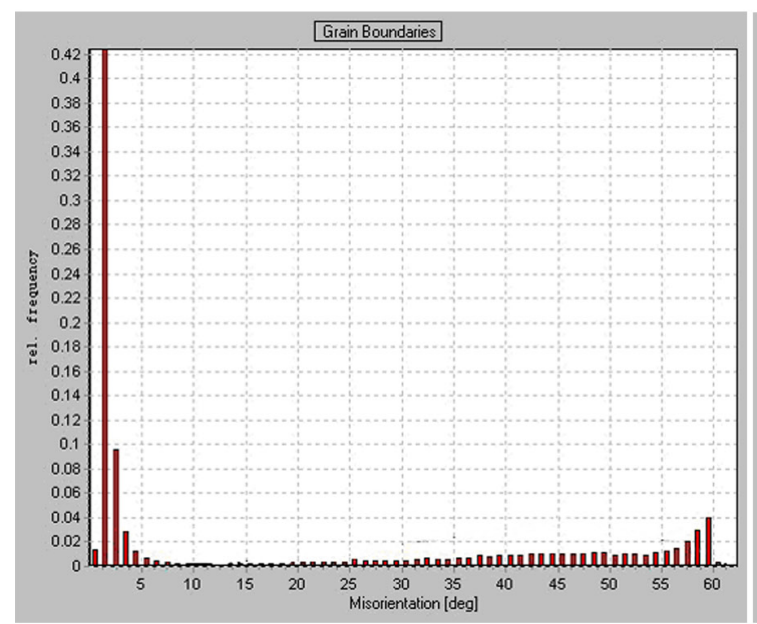

(e)

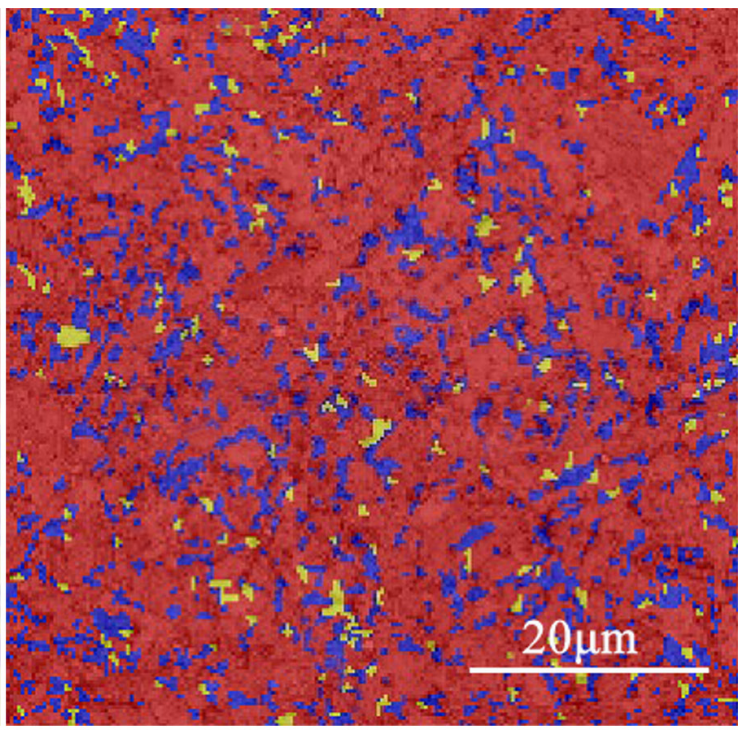

(b)

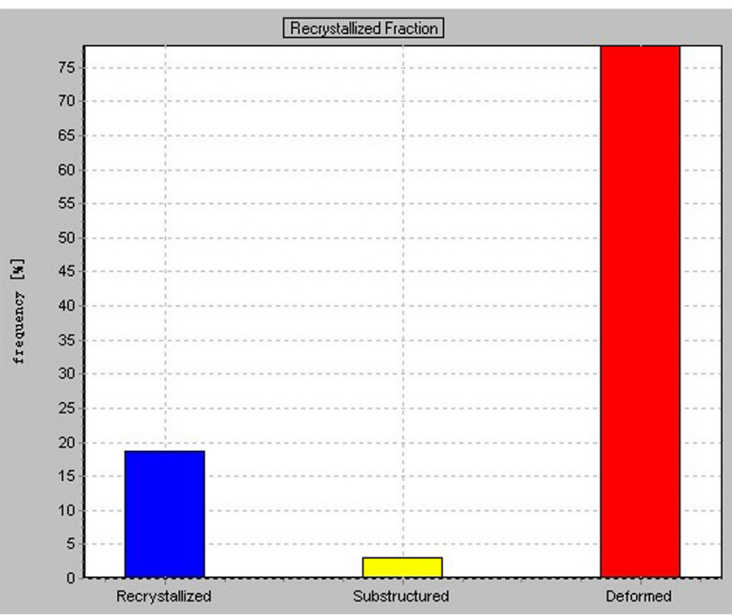

(d)

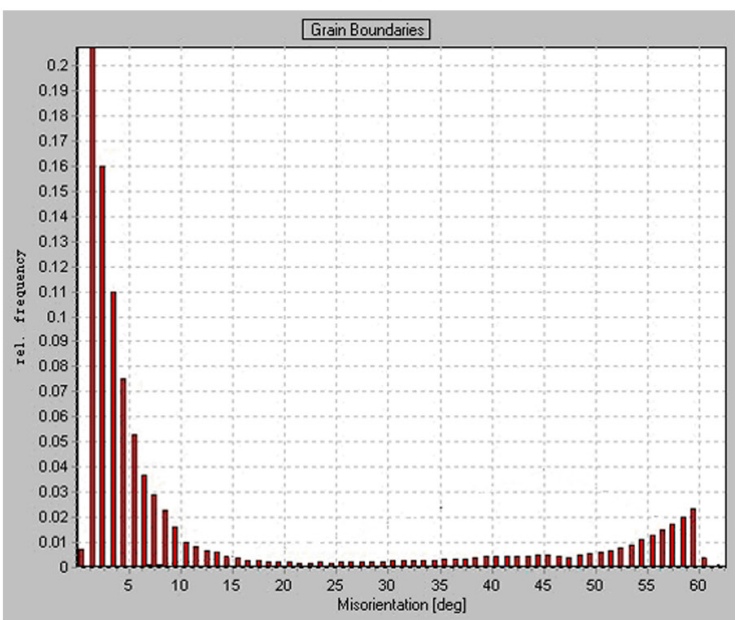

(f)

Figure 2. (a) and (b) DefRex $+B C$ contrast maps of the first and second samples respectively; (c) and (d) histograms showing the volume fractions of the recrystallized grains, grains with substructures and deformed grains in the microstructures of the first and second copper samples respectively; (e) and (f) histograms showing the distribution of the grain boundary misorientations in the microstructures of the first and second copper samples respectively. 


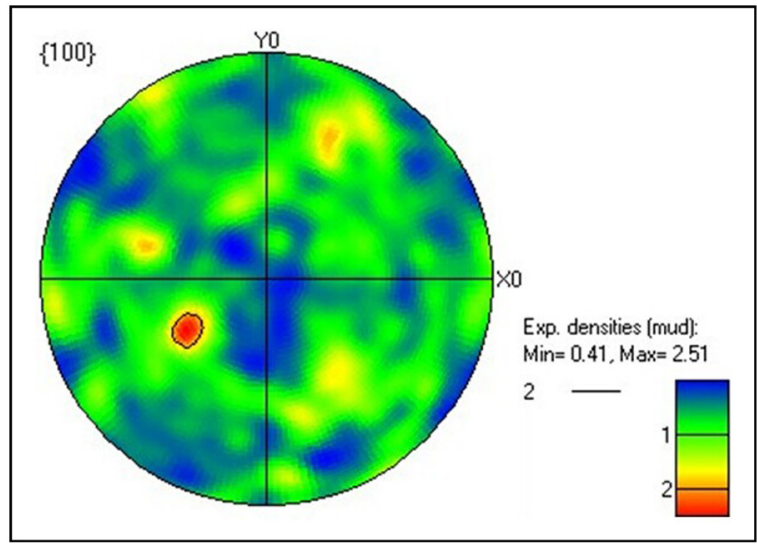

(a)

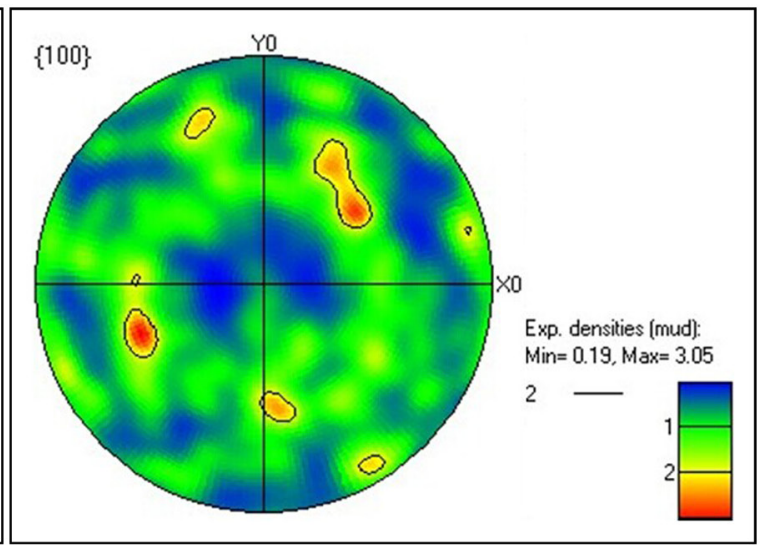

(b)

Figure 3. $\{100\}$ pole figures of (a) the first copper sample and (b) the second copper sample.

the powder particles. The increase of the dislocation density can cause formation of a large number of dislocation cells which then turns into a large number of substructures with increasing the amount of plastic deformation, as shown in Figure 2c. When the copper powder compact was heated and pressed in the SPS furnace, the high density of dislocations and associated storage of internal energy facilitated by the large amount of plastic deformation of the copper powder particles caused die-pressing of the copper powder can cause the system to be thermodynamically unstable and lead to recrystallization which will relieve the stored internal energy. This is the reasons why the second copper sample has a much higher fraction of recrystallized grains, as shown in Figure 2d.

As shown by the pole figures of the two copper smaples in Figure 3, both samples had a small degree of $\{100\}$ texture along directions incline to the $\mathrm{Z}$ axis which is along the direction of the pressing force during die-pressing and SPS. It can be envisaged that the low degree of texture has little effect on the mechanical properties of the consolidated copper samples. This works shows that the materials prepared by consolidation of metal powders using SPS do not have a high degree of texture.

Figure 4 shows the typical tensile engineering stress-strain curves of the two consolidated copper samples. From Figure 4, it can be seen that the yield stength, ultimate tensile strength and elongation to fracture of the first copper sample were all clearly better than those of second copper sample. This shows that the consolidation state of the first copper sample is clearly better than that of the second sample. As also can be seen from the Figure 4, both copper samples exhibited strain hardening after yielding which are typical for ingot metallurgy copper due to the low stacking fault energy of copper. The fact that the mechanical strength and deformation behaviour of both consolidated copper samples are virtually same as ingot metallurgy copper shows that for both consolidated copper samples, the level of consolidation is fairly high, being close to $100 \%$. The residual waekly bonded interparticle boundaries can cause decrease of strength and ductility.

As shown by fracture surfaces of the tensile test specimens cut from the two copper samples in Figure 5a-d, the fracture mode of both consolidated copper samples was ductile

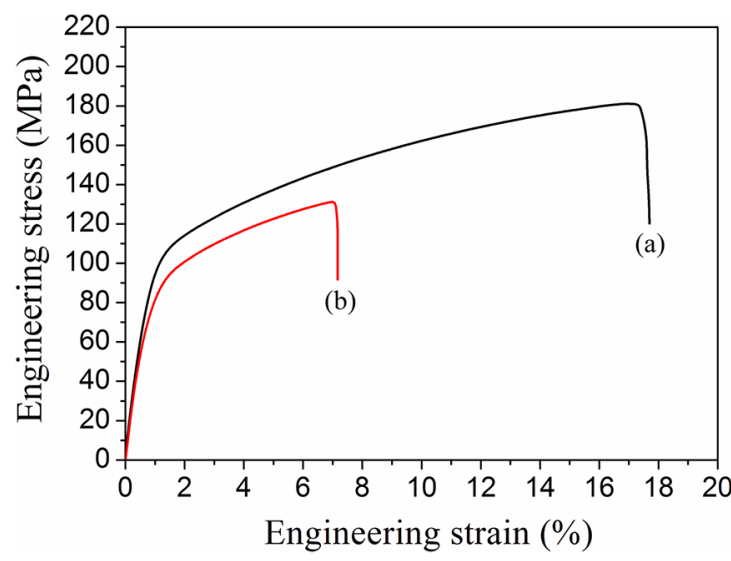

Figure 4. The typical tensile engineering stress-strain curves of the specimens cut from (a) the first copper sample and (b) the second copper sample.

fracture, as demonstrated by the large number of small dimples shown on the fracture surfaces. In the mean time, the fracture surfaces of the tensile test specimens cut from both copper samples showed deep cavities, as indicated by the arrows in Figure 5a, c, and the fracture suefaces of the tensile test specimens cut from the second copper sample also showed microcracks as indicated by the double arrows in Figure 5c. Fewer cavities were observed in the fracture surfaces of the tensile test specimens cut from the first copper sample than in the fracture surfaces of the tensile test specimens cut from the second copper sample. As shown in Figure 5e, f, there were more cavities and microcracks shown in the longitudinal cross sections of the tensile test specimens cut from second copper sample than those in the first copper sample. The cavities and microcracks are formed by separation of the powder particles caused by the tensile stress during tensile testing, so the number and size of them reflect the level of consolidation. This work shows that compacting copper powder prior to SPS has negative effect on the consolidation level achieved by SPS under the same condition. The reason for this is likely to be that the 


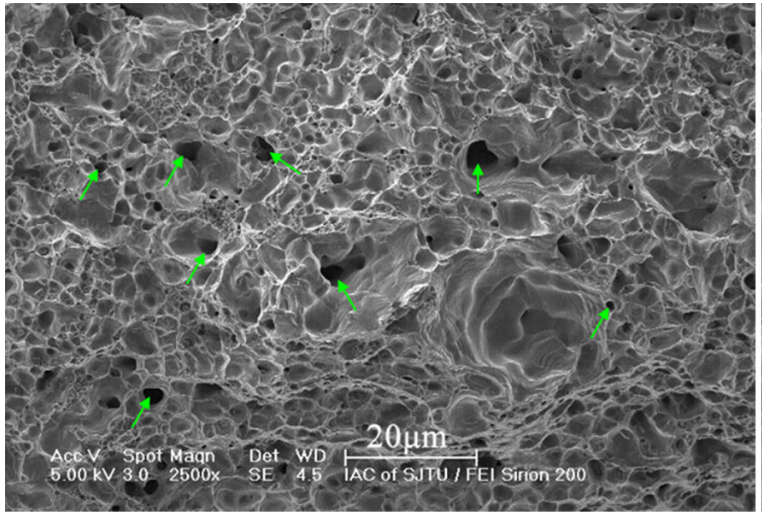

(a)

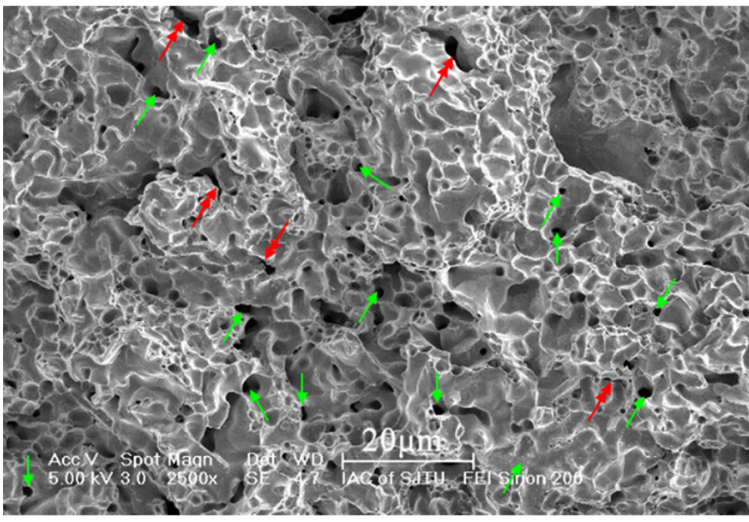

(c)

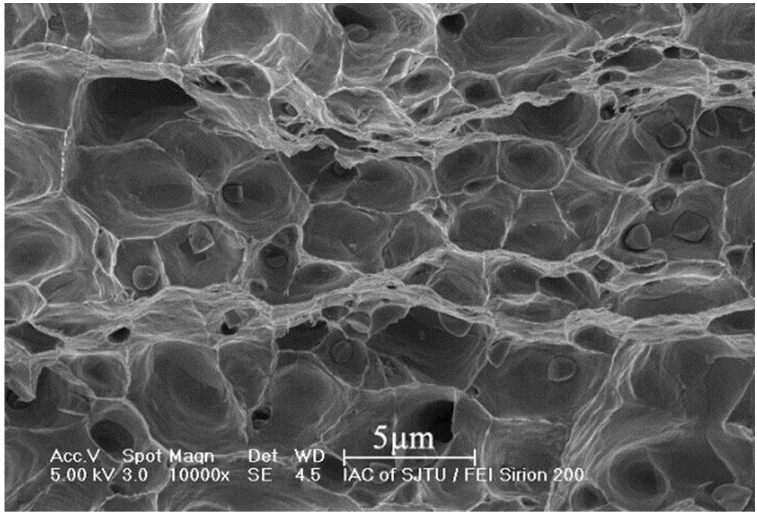

(b)

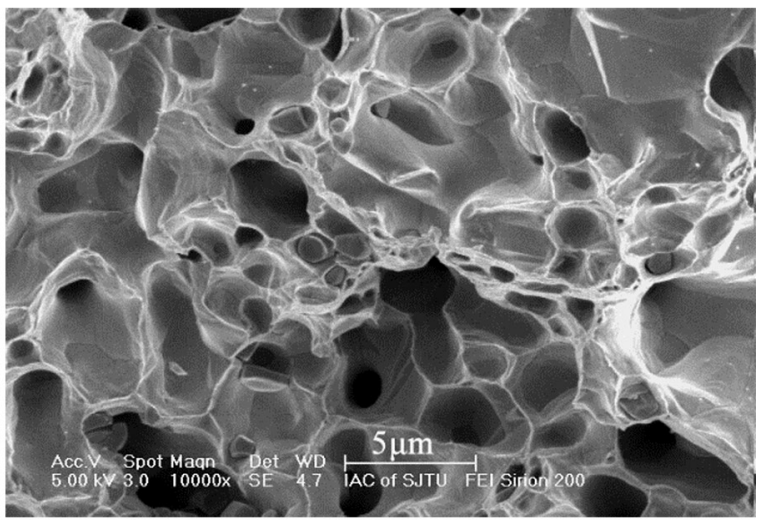

(d)

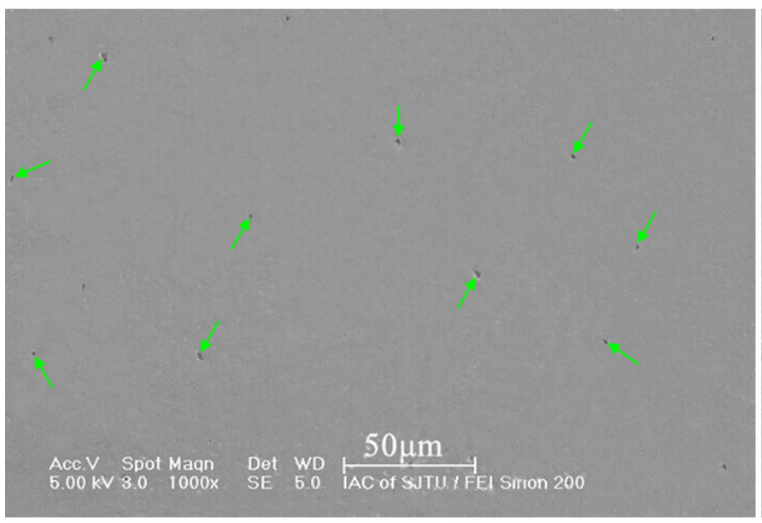

(e)

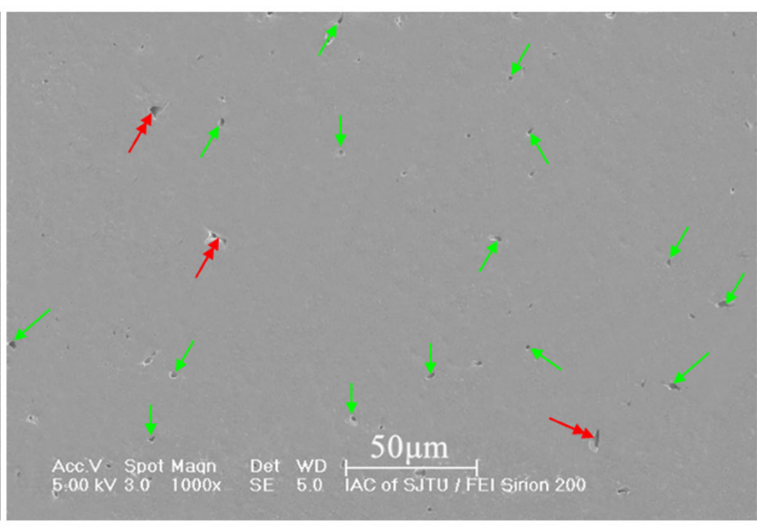

(f)

Figure 5. (a) and (b) SEM secondary electron images of the fracture surface of a tensile test specimen cut from the first copper sample; (c) and (d) SEM secondary electron images of the fracture surface of a tensile test specimen cut from the second copper sample; (e) and (f) SEM secondary electron images of the longitudinal cross sections of the tensile tested specimens cut from the first and second copper samples respectively. Single arrows indicate the cavities in (a), (c), (e) and (f) and double arrows indicate microcracks in (c) and (f).

larger gaps between powder particles in a loose powder are favourable for generating sparks from pulse current, and thus SPS is more effective in activating the copper powder particle surfaces, and lead to better bonding when the particles are deformed and pressed togerthe by applying a pressure.

As shown in Figure 5e, f, the volume fraction of cavities and microcracks in both copper samples are quiate low, being less than $5 \%$, confirming that the level of consolidation of both copper samples is quite high, being close to $100 \%$.

\section{Conclusions}

(1) The first copper sample prepared by direct SPS of gas atomized copper powder at $800{ }^{\circ} \mathrm{C}$ and the second copper sample prepared by SPS of a copper powder compact at $800{ }^{\circ} \mathrm{C}$ both have an equiaxed grain structure containing a large number of annealed twins, with the former having coarser grains than the latter. The first copper sample has 
a substantial fraction of grains with substructures, while the second copper sample has a substantial fraction of recrystallized grains. The difference in the microstructures of the two samples is due to the difference in the amount of plastic deformation of the copper powder particles.

(2) The yield strength, ultimate tensile strength and elongation to fracture of the first copper sample are clearly better than those of the second copper sample, due to the fact that the second copper sample contains a large number of weakly bonded interparticle boundaries. This shows that die-pressing of the copper powder prior to SPS has

\section{References}

1. Zhang JG, Wang LM, Zhang SM, Wang LS and Zhang JH. The copper and copper alloy powders application and research status. Powder metallurgy industry. 2013; 23(1):52-57.

2. Wong-Ángel WD, Téllez-Jurado L, Chávez-Alcalá JF, ChaviraMartínez E and Verduzco-Cedeño VF. Effect of copper on the mechanical properties of alloys formed by powder metallurgy. Materials \& Design. 2014; 58:12-18. http://dx.doi.org/10.1016/j. matdes.2014.02.002.

3. Boland CD, Hexemer RL Jr, Donaldson IW and Bishop DP. Industrial processing of a novel $\mathrm{Al}-\mathrm{Cu}-\mathrm{Mg}$ powder metallurgy alloy. Materials Science and Engineering A. 2013; 559:902-908. http://dx.doi.org/10.1016/j.msea.2012.09.049.

4. Wang HL, Zhang R, Hu X, Wang CA and Huang Y. Characterization of a powder metallurgy $\mathrm{SiC} / \mathrm{Cu}-\mathrm{Al}$ composite. Journal of Materials Processing Technology. 2008; 197(1-3):43-48. http:// dx.doi.org/10.1016/j.jmatprotec.2007.06.002.

5. Gökçe A, Fındık F and Kurt AO. Microstructural examination and properties of premixed $\mathrm{Al}-\mathrm{Cu}-\mathrm{Mg}$ powder metallurgy alloy. Materials Characterization. 2011; 62(7):730-735. http://dx.doi. org/10.1016/j.matchar.2011.04.021.

6. Liao J, Yamamoto N and Nakata K. Gas tungsten arc welding of fine-grained AZ31B magnesium alloys made by powder metallurgy. Materials \& Design. 2014; 56:460-467. http:// dx.doi.org/10.1016/j.matdes.2013.11.061.

7. Ružić J, Stašić J, Rajković V and Božić D. Strengthening effects in precipitation and dispersion hardened powder metallurgy copper alloys. Materials \& Design. 2013; 49:746-754. http:// dx.doi.org/10.1016/j.matdes.2013.02.030.

8. Ullbrand JM, Córdoba JM, Tamayo-Ariztondo J, Elizalde MR, Nygren M, Molina-Aldareguia JM, et al. Thermomechanical properties of copper-carbon nanofibre composites prepared by spark plasma sintering and hot pressing. Composites Science and Technology. 2010; 70(16):2263-2268. http://dx.doi. org/10.1016/j.compscitech.2010.08.016.

9. Samal CP, Parihar JS and Chaira D. The effect of milling and sintering techniques on mechanical properties of $\mathrm{Cu}$-graphite metal matrix composite prepared by powder metallurgy route. Journal of Alloys and Compounds. 2013; 569:95-101. http:// dx.doi.org/10.1016/j.jallcom.2013.03.122.

10. Sorkhe YA, Aghajani $\mathrm{H}$ and Tabrizi AT. Mechanical alloying and sintering of nanostructured $\mathrm{TiO}_{2}$ reinforced copper composite negative effect on the consolidation level achieved by SPS under the same condition.

(3) SPS is more suitable for directly consolidating powders than consolidating powder compacts, but overall SPS produce bulk materials with high relative density and good mechanical properties.

\section{Acknowledgements}

The authors would like to thank the National Natural Science Foundation of China (Project approval No.: 51271115) for funding.

and its characterization. Materials \& Design. 2014; 58:168-174 http://dx.doi.org/10.1016/j.matdes.2014.01.040.

11. Zhou DS, Zhang DL, Kong $C$ and Munroe P. Factors controlling the tensile properties of ultrafine structured $\mathrm{Cu}-5 \mathrm{vol} \% \mathrm{Al}_{2} \mathrm{O}_{3}$ nanocomposite prepared by high energy mechanical milling and powder compact extrusion. Materials Science and Engineering $A$. 2013; 584:67-72. http://dx.doi.org/10.1016/j.msea.2013.07.005.

12. Yan P, Lin CG, Cui S, Lu YJ, Zhou ZL and Li ZD. Microstructural features and properties of high-hardness and heat-resistant dispersion strengthened copper by reaction milling. Journal of Wuhan University of Technology-Materials Science Edition. 2011; 26(5):902-907.

13. Novák P, Kubatík T, Vystrčil J, Hendrych R, Kříž J, Mlynár $\mathrm{J}$, et al. Powder metallurgy preparation of Al-Cu-Fe quasicrystals using mechanical alloying and Spark Plasma Sintering. Intermetallics. 2014; 52:131-137. http://dx.doi.org/10.1016/j. intermet.2014.04.003.

14. Cipolloni G, Pellizzari M, Molinari A, Hebda M and Zadra M. Contamination during the high-energy milling of atomized copper powder and its effects on spark plasma sintering. Powder Technology. 2015; 275:51-59. http://dx.doi.org/10.1016/j. powtec.2015.01.063.

15. Sule R, Olubambi PA, Sigalas I, Asante JKO, Garrett JC and Roos WD. Spark plasma sintering of sub-micron copper reinforced with ruthenium-carbon nanotube composites for thermal management applications. Synthetic Metals. 2015; 202:123-132. http://dx.doi.org/10.1016/j.synthmet.2015.02.001.

16. Zhang ZH, Wang FC, Lee SK, Liu Y, Cheng JW and Liang Y. Microstructure characteristic, mechanical properties and sintering mechanism of nanocrystalline copper obtained by SPS process. Materials Science and Engineering A. 2009; 523(1-2):134-138. http://dx.doi.org/10.1016/j.msea.2009.07.016.

17. Sule R, Olubambi PA, Sigalas I, Asante JKO and Garrett JC. Effect of SPS consolidation parameters on submicron $\mathrm{Cu}$ and $\mathrm{Cu}-\mathrm{CNT}$ composites for thermal management. Powder Technology. 2014; 258:198-205. http://dx.doi.org/10.1016/j. powtec.2014.03.034.

18. Diouf S, Fedrizzi A and Molinari A. A fractographic and microstructural analysis of the neck regions of coarse copper particles consolidated by spark plasma sintering. Materials Letters. 2013; 111:17-19. http://dx.doi.org/10.1016/j.matlet.2013.08.056. 